University of Windsor

Scholarship at UWindsor

\title{
Student perception of academic grading: personality, academic orientation, and effort
}

\author{
Gregory K. Tippin \\ Lakehead University \\ Kathryn Lafreniere \\ University of Windsor \\ Stewart Page \\ University of Windsor
}

Follow this and additional works at: https://scholar.uwindsor.ca/psychologypub

Part of the Psychology Commons

\section{Recommended Citation}

Tippin, Gregory K.; Lafreniere, Kathryn; and Page, Stewart. (2012). Student perception of academic grading: personality, academic orientation, and effort. Active Learning in Higher Education, 13 (1), 51-61. https://scholar.uwindsor.ca/psychologypub/47

This Article is brought to you for free and open access by the Department of Psychology at Scholarship at UWindsor. It has been accepted for inclusion in Psychology Publications by an authorized administrator of Scholarship at UWindsor. For more information, please contact scholarship@uwindsor.ca. 


\title{
Student perception of academic grading: personality, academic orientation, and effort
}

Gregory K. Tippin, Lakehead University, Psychology Department, Thunder Bay, Ontario, Canada P7B 5E1. Fax: (807) 346-7734. Email: gtippin@lakeheadu.ca

Dr. Kathryn D. Lafreniere, University of Windsor, Psychology Department, Windsor, Ontario, Canada N9B 3P4. Phone: (519) 253-3000 ext. 2233. Fax: (519) 973-7021. Email: lafren1@uwindsor.ca

Dr. Stewart Page, University of Windsor, Department of Psychology, Windsor, Ontario, Canada N9B 3P4. Phone: (519) 253-3000 ext. 2243. Fax: (519) 973-7021. Email: page@uwindsor.ca

\section{Biographical details of authors}

Gregory Tippin is a M.A. Clinical Psychology candidate at Lakehead University. His research interests are in effort perception in academia, mental illness stigma, and mental health treatment and patient outcomes, specifically collaborative approaches to patient care.

Dr. Kathryn Lafreniere is a Professor of Psychology in the Psychology Department of the University of Windsor. Her research interests are in health and community psychology, and are primarily concentrated in the areas of women's health and prevention issues, youth risk and resilience, and personality and health.

Dr. Stewart Page is a University Professor of Psychology in the Psychology Department of the University of Windsor. His current interests are in personality, social psychology, ranking procedures for evaluation of universities, and generally the study of higher education in North America as it exists today.

\begin{abstract}
Factors influencing student perceptions of academic grading were examined, with an emphasis on furthering understanding of the relevance of effort to students' conceptualization of grading. Students demonstrated a conceptualization of grading where effort should be weighted comparably to actual performance in importance to the composition of a grade, with the expectation that grade allocation should reflect this perception. Students suggested a compensatory effect of effort in grade assignment where a subjectively perceived high level of effort was expected to supplement low performance on a task. Furthermore, students perceived professors as less fair and less competent when professors were perceived to not be able to adequately account for students' subjective perception of effort. In addition, student perceptions of grading were examined in relation to student possessed learning orientation (LO), grade orientation (GO), and aspects of personality. Prototypically, individuals high in LO tend to be motivated by the acquisition of knowledge, while those high in GO tend to be driven by the acquisition of high grades. Conscientiousness, openness and age contributed significantly to and positively predicted LO. Inversely, conscientiousness, openness and age contributed significantly to and negatively predicted GO while neuroticism positively predicted this orientation. Students' appear to place a heavy amount of importance in professor consideration of effort, despite recognizing the realistic difficulties in determining effort. The potential for an emerging student mentality is discussed, where students' perception of grading is distorted by a subjective appraisal of their own effort.
\end{abstract}

\section{Keywords}

academic achievement, effort, academic grading, student attitudes, academic orientation, personality traits 


\section{Student perception of grading}

Present in academia is a disconnect between students and faculty in expectation, perception, and reasoning behind academic evaluation, manifesting in varying perception of the process of grading and of what constitutes a deserved grade from the perspective of assessor and assessee. Goulden and Griffin (1997) suggested that students believe grades to be derived using established standards more than faculty report that they actually are, reflecting both the potential subjectivity of the grading process and student misconceptions of the evaluation process. Due to the differing roles of students and faculty in the academic environment, there is bound to be dispute regarding how grades should be appropriately and fairly assigned and what should be taken into consideration in grading. Discrepancies in expectation and perception produce a situation with ample opportunity for misunderstanding and conflict between faculty and students and may be representative of a generally distorted student perception of the purpose of academia and evaluations (Greenberger et al, 2008).

Research has demonstrated that students and faculty agree that effort and actual performance are the central criteria in evaluation, with both parties assigning greater significance to mastery of material than to effort (Adams, 2005; Gaultney and Cann, 2001). However, in weighting the importance of effort and performance in the desired composition of a grade, students have demonstrated a skewed perception of effort importance to assessment, allocating $38 \%$ to effort and $62 \%$ to performance where faculty attribute $17.2 \%$ and $82.8 \%$, respectively (Adams, 2005). Furthermore, with regard to specific academic attitudes and behaviours, $40 \%$ of students reported feeling deserving of a grade of $B$ for doing the majority of the reading for a course and $34 \%$ felt a $B$ was deserved for attending most classes (Greenberger et al., 2008). These findings suggest that in addition to having a skewed perception of grade component weighting, student perception of the components themselves may also be distorted, with axiomatic student behaviour, such as reading and attendance, worthy of above average recognition. Such findings suggest the need for better understanding of students' perception of grading, specifically the relationship between varying levels of both effort and performance and elucidation of factors relevant to students' effort emphasis.

\section{Student perception of faculty and the grading process}

Findings demonstrating the heightened level of importance students assign to faculty consideration of effort raise questions regarding both the ability of faculty to actually measure effort as well as the justification of such a pursuit. Academic assessment is typically a measure of the performance of the individual, where the relationship between acquired knowledge and displayed performance is assumed to be representative and concordant (Gibbs and Simpson, 2002). Educational evaluation is built upon this assessment of what students are able to demonstrate as opposed to perhaps a more desirable evaluation of what knowledge students possess or what learning has occurred (Race, 2005). Instead, performance is the factor considered to be most representative of mastery of material and thus is most heavily weighted by faculty (Adams, 2005). From the perspective of faculty, if mastery of material cannot be adequately demonstrated, it must be assumed that the student is not adequately prepared to proceed. Regardless of any potential argument of the legitimacy of effort consideration in grading, the realities of faculty ability in the demands of the academic environment, where the logistics of effort consideration make such an endeavor problematic if not impossible, render effort inconsequential to academic assessment. As a result, faculty's necessary reliance on performance results in the need for students to appropriately communicate their knowledge or understanding in assessment (Race, 2005).

Despite understanding the inability of faculty to appropriately assess effort in grade allocation (Gaultney and Cann, 2001), students continue to perceive effort and its consideration as important to assessment. These findings suggest either a persistent unreasonableness in the expectations of students or perhaps a gap in student understanding or faculty communication in the process and purpose of assessment. This conflict between student desire and reality creates the potential for student frustration in a situation where faculty-evaluated performance is discordant with students' perceived effort and its importance to assessment. The consequences in such a situation of ostensible incongruity between effort and 
performance is of particular interest regarding students' judgments of faculty competency and fairness, especially with regard to the aforementioned findings of student understanding of the difficulty of effort assessment. Research has been inconsistent in understanding the potentially conditional nature of students' evaluations of faculty, with some research suggesting a relationship between grade attainment and positive faculty attribution (for example, Snyder and Clair, 1976) and others claiming the legitimacy of this relationship to be a myth (Aleamoni, 1999). Furthermore, research has attempted to delineate the necessary conditions for attainment of valid student assessment of faculty, with a wide variety of factors relevant to the uniqueness of a given academic situation (Marsh and Roche, 1997). However, there is a gap in understanding the influence of the perceived importance of effort consideration with regard to subsequent student evaluation of faculty. More specifically, because of the significant importance students have attributed to faculty consideration of exerted effort, it is important to understand the impact of a failure to appropriately consider effort in grade composition on students' judgment of faculty fairness and competence.

\section{Student characteristics}

Findings of students' continued desire for effort consideration and its perceived importance to assessment despite understanding of its immeasurability raises questions regarding the origin of such student beliefs. This is further emphasized by aforementioned findings of exaggerated perceptions of grade entitlement as a result of subjectively perceived effort (Greenberger et al., 2008). Examination of students' approaches and general orientation toward academia may facilitate understanding of the underpinnings of their beliefs regarding academic grading practices, including the importance of effort.

Research has examined students' approaches toward the process of learning, delineated between a surface level approach, where learning is shallow memorization with a goal of recall, and a deep level approach, where learning is directed more toward understanding (Gibbs and Simpson, 2002). From the perspective of the academic ideal, student pursuit of a deep level approach to learning is most representative and is traditionally espoused in academia, where more meaningful comprehension and knowledge acquisition is conceptualized to occur. However, the reality of contemporary academic assessment has been suggested to have difficulty appropriately assessing this idealized deep level learning and also of utilizing assessments which tend to result in strategic learning by students, where a surface level approach toward the study of only material likely to be assessed is used (Race, 2005; Gibbs and Simpson, 2002).

Interestingly, research has also suggested external influences on students' utilized level of learning. Students of teachers who have received increased skill training tend to adopt a deeper level approach to learning compared to students of teachers without skill training (Gibbs and Coffey, 2004), suggesting the role of teacher skill in the quality of students' approach toward learning. Furthering the relationship between teachers' approach and students' learning level approaches, research has demonstrated a relationship to test format, where a surface level approach has been shown to be more prominent with a multiple choice assessment and a deep level approach most common in essay (Scouller, 1998) or presentation assessments (Race, 2005). While a deep level of learning approach is generally assumed to enhance performance, this may be limited to situations requiring more than verbatim recall of source material (Säljö, 1981). Indeed, while deep level learners typically show more success in essay format assessment, this is not true for multiple choice assessment, where the surface learning level approaches elicited by this format tend to be more successful than deep level learning. With the demands of early level post-secondary class sizes and the largely multiple choices based assessments of these students, surface level approaches appear then to be somewhat adaptive. However, with later academic years typically associated with a decreased reliance on multiple choice based assessment, continued student reliance on surface level approaches may prove problematic. With regard to effort, a student approaching learning at the surface level may complete several hours of work, amounting to a perception of a significant amount of effort, yet perform discordantly poorly, as a result of the shallow depth of learning (Kember et al., 1996 as cited in Gibbs and Simpson, 2002), especially in an assessment requiring a deeper level of understanding. From the perspective of the student, exerted effort is not being appropriately represented by performance, potentially leading to frustration. 
Research has demonstrated that surface level learning approaches are often engaged in by individuals oriented toward grade acquisition as opposed to understanding of material (Gibbs and Simpson, 2002; Race, 2005), suggesting a more general orientation toward academia of students utilizing such an approach. The potential for understanding the general academic motivation of students may provide further understanding of the characteristics that underlie potentially problematic academic behaviours and attitudes, such as an emphasis on effort consideration. In an attempt to better elucidate students' attitudes and general approach toward academia and achievement, research has suggested the existence of two orientations in post-secondary populations, delineated between a learning orientation (LO) and a grade orientation (GO) (Eison, 1981). Theoretically, individuals high in LO have an internal focus toward knowledge acquisition and mastery of material; while understanding the importance of grades, they are not their primary motivator. In contrast are those high in $\mathrm{GO}$, whose primary motivation is extrinsic in the attainment of high grades. These two orientations are not mutually exclusive and aspects of both may be present in students (Eison et al, 1986). Although research has identified academic attitudes and behaviours common to each orientation (Eison, 1982; Eison et al., 1986; Page and Alexitch, 2003), a gap exists linking established personality characteristics to academic orientation. Further research may assist in determining why students subscribe to a particular academic orientation while identifying origins of subsequent academic attitudes, behaviours, and perceptions of the grading process, specifically effort, performance, and faculty ability.

The purpose of this study was to explore how students would assign grades and judge the fairness and competence of a professor based on their interpretation and response to hypothetical scenarios which varied in their depiction of student effort and performance A secondary aim of this investigation was to examine student characteristics that predict orientation toward academia and perceptions of grading. The study addressed the following questions:

1. How are students' perceptions of grading influenced by effort and actual performance?

2. What is students' perception of the grading process, specifically professors' grading fairness and competence?

3. What is the relationship between student characteristics such as academic orientation and personality characteristics and students' perceptions of grading?

\section{Method}

Questionnaires were completed by 120 undergraduate student volunteers in exchange for a bonus point in various psychology courses. Participants consisted of 100 females (83.3\%) and 20 males (16.7\%) ranging from 18 to 52 years of age $(M=21.7, S D=5.4)$. Ninety $(75.0 \%)$ were arts and social science majors, fifteen (12.5\%) were science majors, and the remaining fifteen $(12.5 \%)$ were from various other disciplines including engineering, human kinetics, nursing, business, and undeclared majors. Thirty-two $(26.7 \%)$ were in their first year of academic study, $25(20.8 \%)$ in their second, $31(25.8 \%)$ in their third, and $32(26.7 \%)$ in their fourth year.

Participants completed a measure consisting of one of four randomly assigned hypothetical scenarios followed by the LOGO-II scale of academic orientation (Eison et al., 1986), the BFI-10 personality inventory (Rammstedt \& John, 2007), items addressing academic attitudes, and general demographic questions. Each scenario described a hypothetical situation where a student had put forth either high or low effort toward the completion of an assignment resulting in either high or low performance, creating four potential scenarios, as developed by Adams (2005) and Sabini and Monterosso (2003). Based on the information given, participants were asked to assign a letter grade, ranging from $F$ to $A_{+}$, to the scenario and explain the rationale behind their choice. This was followed by items assessing attitudes toward professors' grading fairness and competence.

To determine participant academic orientation, the LOGO-II scale was used to determine the learning and grade orientation of students. The learning and grade orientation scales have demonstrated reliability with Cronbach's alpha coefficients of .76 and .73, respectively (Levine, 2003). The present study found comparable, if slightly lower, reliability with Cronbach's alpha of .58 for LO and .67 for GO. 
The BFI-10 personality inventory was used to measure students' personality characteristics. Consisting of 10 items measuring the five major traits of personality (extraversion, agreeableness, conscientiousness, neuroticism, and openness), the BFI-10 is a more concise measure of personality than the traditional BFI while maintaining significant reliability and validity (Rammstedt \& John, 2007).

A final item required participants to assign a percentage to the importance of effort and performance respectively in a grade of $100 \%$ (Adams, 2005), followed by general demographic questions.

\section{Results}

Scenario depicted effort and performance and grade assignment

In weighting effort and performance toward a general grade of $100 \%$, participants as a group allocated $61 \%$ to performance $(S D=17.10)$ and $39 \%$ to effort $(S D=17.10)$.

To examine the effect effort and performance depiction had on students' perception of grading, grade assignment, perception of professors' grading fairness, and perception of professors' grading competency were measured. For grade assignment by participants, each letter grade was weighted on a scale of 13 to 1 with 13 representing the highest possible grade assigned $(A+)$ and 1 the lowest $(F)$. To assess the effects of scenario on resulting grades given by participants, a $2 \times 2$ factorial ANOVA was conducted with significant main effects found for effort, $F(1,116)=131.96, p<.001$, and performance, $F(1,116)=$ $184.83, p<.001$. With regard to participant grade assigned, scenarios describing high effort $(M=9.87$, $S D=2.36)$ or high performance $(M=10.2, S D=2.54)$ resulted in the highest assigned grades, with an average grade of $B+$, while those describing low effort $(M=6.23, S D=3.12)$ or low performance $(M=$ $5.9, S D=2.49$ ) elicited the lowest assigned grades, with an average grade of $C$. The interaction between effort and performance was not found be significant with regard to grade allocation.

\section{Scenario depicted effort and performance and professor grading fairness}

The influence of scenario effort and performance depiction on subsequent perception of professors' grading fairness was examined using a $2 \times 2$ factorial ANOVA. There was a significant interaction between performance and effort, $F(1,116)=6.01, p<.05$, with participants rating a scenario containing high effort/low performance least likely to be fairly graded $(M=3.37, S D=.77)$ and high effort/high performance most likely $(M=4.1, S D=.55)$, as shown in Figure 1. A main effect was found for performance, $F(1,116)=8.66, p<.01$, with scenarios containing high performance perceived more likely to be fairly graded by faculty $(M=3.85, S D=.73)$ than low performance $(M=3.45, S D=.79)$.

$<$ Insert Figure 1 here $>>$

Scenario depicted effort and performance and professor grading competency

Finally, the effect of scenario depicted effort and performance on participants' subsequent perception of faculty grading adequacy was examined. A $2 \times 2$ factorial ANOVA found a significant interaction between effort and performance, $F(1,116)=6.92, p<.01$, and shown in Figure 2. Participants believed professors to be most competent at grading in a high effort/high performance scenario $(M=3.93, S D=.52)$ and least competent in a high effort/low performance scenario $(M=3.23, S D=1.01)$ where faculty's evaluations would not take the high effort into consideration, consistent with participant perception of grading fairness.

$<$ Insert Figure 2 here $>>$

Personality predictors of academic orientation

From the LOGO-II measure, LO was found to be significantly negatively associated with the level of grade assigned to a given scenario, $r(120)=-.20, p<.05$, where participants higher in LO assigned lower 
overall grades. To determine aspects of personality predicting learning or grade orientation, a standard multiple regression was conducted based on factors found to correlate with those outcome measures. The regression model for LO was found to be significant, $R^{2}=.143, F(3,116)=6.44, p<.001$. Analysis of the individual factors found age $\left(\mathrm{sr}^{2}=.04\right)$, conscientiousness $\left(s r^{2}=.04\right)$, and openness $\left(s r^{2}=.06\right)$ were all significant predictors of a LO accounting for $4 \%, 4 \%$, and $6 \%$ of the unique variance, respectively. The regression model for $\mathrm{GO}$ was also found to be significant, $R^{2}=.184, F(4,115)=6.48, p<.001$. Of the predictor variables, age accounted for $5 \%\left(s r^{2}=.05\right)$, conscientiousness $3 \%\left(s r^{2}=.03\right)$, openness $3 \%\left(s r^{2}\right.$ $=.03)$, and neuroticism $5 \%\left(s r^{2}=.05\right)$ of the unique variance in GO.

\section{Discussion and conclusions}

The influence of effort and performance on student grade allocation

Findings added further support to evidence of student perception of effort, with students demonstrating a clear bias in the importance placed on effort consideration in grade composition. With regard to student perceptions of the weighted components of a grade, students expressed a desired 60/40 split respectively between performance and effort, replicating past findings (Adams, 2005) and raising concerns regarding students' understanding of both the process and purpose of academic evaluations.

Students further exemplified their perception of effort importance when given the opportunity to grade hypothetical scenarios depicting varying effort and performance. With regard to scenario and subsequent grade allocation, both effort and performance were found to have significant effects. Scenarios featuring high effort or high performance elicited higher assigned grades from students, each averaging an assigned grade of $B+$, while scenarios of low effort or low performance elicited the lowest grades, each averaging an assigned grade of $C$. The main effect of effort in grade allocation suggests that students reward effort in the same manner as performance when assigning academic grades, and that grades assigned based on effort are independent of actual performance.

Scenarios depicting low effort or low performance both elicited average grades of $C$, indicating the expectation of an average grade even when a student was described as exhibiting low performance and failing to meet minimum requirements. These findings were emphasized in a follow-up question asking students' to justify their grade assignment, rationalizing, "The student could have handed in nothing," or, "The student did after all submit the work", reflecting an apparent sense of self-entitlement, or the rewarding of effort at a level discordant to the actual mediocre performance (Greenberger et al., 2008). Participants appeared to find assignment submission in itself deserving of not only a passing grade, but also an average grade of $C$, raising concerns regarding student expectations of achievement criteria. Thus, students justified their perception with a conceptualization of effort exertion below the traditionally accepted minimal requirement to have an assessment even considered for evaluation, namely, assignment submission. These results support past findings of students' exaggerated perception of their exerted effort and the degree to which that effort should be rewarded (Adams, 2005; Greenberger et al., 2008).

The influence of effort and performance on student perception of the grading process

Students demonstrated the extent of effort significance in their perception of grading as performance and the interaction between performance and effort were found to significantly influence perceptions of professors' grading fairness, further illustrating student judgment of faculty inability to consider effort. A scenario of high effort/high performance was found most likely to be fairly graded by professors, while a scenario of high effort/low performance, where a discrepancy between effort and performance existed, was found least likely to be fairly graded. Findings appear to suggest that students judge professors as unfair when the perceived effort invested in the completion of an assignment does not compensate for actual poor performance, again despite professors' inability to take into account factors related to the process of assignment completion.

Understanding of the degree of students' negative evaluation of faculty inability to assess and account for effort in grading was further provided by assessment of students' perception of faculty competency. The grading competency of professors was found to be significantly related to the interaction between 
scenario depicted effort and performance. Professors were perceived most competently able to grade in a high effort/high performance scenario and least able in a high effort/low performance scenario. These findings suggest that the consideration of effort is so essential to students' perception of academia that it extends to their confidence in faculty ability to competently evaluate, with the failure to consider effort indicative of professor incompetency. Mirroring student perceptions of grading fairness, the grading competency of professors was deemed only slightly higher in a low effort/high performance scenario compared to a high effort/low performance scenario despite the discrepancy in actual performance. The present findings of dissatisfaction with the inability of professors to account for subjective effort exertion in a poorly completed assignment further supports past findings of a student mentality of unrealistic attitudes and expectations (Adams, 2005; Greenberger et al., 2008).

The relationship between personality, academic orientation, and grading

Regarding academic orientation and grading, individuals higher in learning orientation assigned overall lower grades regardless of scenario, suggesting more stringent or critical academic criteria. Students higher in LO tend to subscribe to a more intellectually oriented and knowledge based approach to education (Eison et al., 1986), which may lead to a general distancing from grade achievement focus, or potentially heightened academic expectations. Regarding personality characteristics and academic orientation, older age, and higher conscientiousness and openness were significant predictors of learning orientation, collectively accounting for a total $14 \%$ of the variance in LO. Conversely, and mirroring the findings for LO, grade orientation was found to negatively correlate with age, conscientiousness, and openness, in addition to correlating positively with neuroticism, with these factors combining to account for $16 \%$ of the variance in GO. Regarding age and academic orientation, these findings appear to suggest an age difference corresponding to adopted academic orientation, with older students ostensibly being more learning orientated and less grade oriented than younger students.

Characteristics of a student high in LO tend to coincide with requirements often sought after in university students, including self-discipline, independence, and an openness to experience resulting in intellectual curiosity, creativity, and an open attitude. Conversely, personality characteristics associated with students high in GO were academically less desirable with more neurotic, undisciplined, conforming, and uncreative students typified by this orientation. These students appear to possess personality traits which are traditionally conceptualized as less ideal in an academic environment. These findings are consistent with research of characteristics representative of each academic orientation (Eison, 1982; Eison et al., 1986; Page and Alexitch, 2003) while elucidating personality characteristics common to each orientation toward academia. Such understanding assists in prediction and identification of potentially problematic academic behaviours and perceptions of students, providing the opportunity for appropriate intervention with these individuals in order to increase comprehension of the realities and purpose of academic study and evaluation.

There were several limitations to the research. With regard to the sample used, the size was relatively small, largely female, and primarily enrolled in arts and social science programs, potentially limiting the generalizability of the findings. Furthermore, research was conducted at a single post-secondary institution, necessitating a more broad assessment of students in future studies. While there was a fairly even distribution of participants across the four academic years of study, the number of students at each level was too small to permit comparisons by year, and future research may benefit from increased attention to student differences in effort perception based on year of academic study.

Exaggerated perceptions of effort importance may exist as only one manifestation of an emerging or present student mentality, where academic attitudes and behaviours are distorted from those traditionally extolled in academia. Student desire for professors' consideration of effort in grade allocation suggests a focus on ensuring higher grade acquisition through the incorporation of additional elements in the marking process other than actual performance. This grade oriented academic style has been described as characteristic of students possessing a sense of entitlement, where achievement is not earned but expected (Greenberger et al., 2008), suggesting a perception of higher learning as a commodity rather than a privilege. However, while the idea of academia as a strictly knowledge-focused realm is noble, the consequences of students' grade attainment is significant and ubiquitous in academia, potentially influencing students' perception of and attitudes toward academia. The potential for competitive grade 
achievement to result in an overemphasis on achievement and a subsequent frustration for the failure of performance to reflect effort is a reality deserving faculty consideration. These difficulties in student perception may be mitigated through the use of improved communication to students of the purpose and process of academic assessment, where ensuring both parties are on the same page may assist in turning the page on the importance students assign to effort consideration in academia.

\section{Acknowledgements}

The authors would like to thank Dr Margaret Flintoff for her helpful comments on an earlier version of the manuscript.

\section{References}

Adams, J. B. (2005) 'What Makes the Grade? Faculty and Student Perceptions', Teaching of Psychology 32(1): 21-24.

Aleamoni, L. M. (1999) 'Student Rating Myths Versus Research Facts from 1924 to 1998', Journal of Personnel Evaluation in Education 13(2): 153-166.

Eison, J. A. (1981) 'A New Instrument for Assessing Students' Orientations Towards Grades and Learning', Psychological Reports 48: 919-924.

Eison, J. A. (1982) 'Educational and Personal Dimensions of Learning- and Grade-Oriented Students', Psychological Reports 51: 867-870.

Eison, J. A., Pollio, H. R., \& Milton, O. (1986) 'Educational and Personal Characteristics of Four Different Types of Learning- and Grade-Oriented Students', Contemporary Educational Psychology 11: 54-67.

Gaultney, J. F., \& Cann, A. (2001) 'Grade Expectations', Teaching of Psychology 28(2): 84-87.

Gibbs, G., \& Coffey, M. (2004) 'The Impact of Training of University Teachers on Their Teaching Skills, Their Approach to Teaching and the Approach to Learning of Their Students', Active Learning in Higher Education 5(1): 87-100.

Gibbs, G., \& Simpson, C. (2002) 'Does your assessment support your students' learning?', www.artsonline.tki.org.nz/documents/GrahamGibbAssessmentLearning.pdf, Milton Keynes, Open University, accessed March 2011.

Goulden, N. R., \& Griffin, C. J. G. (1997) 'Comparison of University Faculty and Student Beliefs About the Meaning of Grades', Journal of Research and Development in Education 31(1): 27-37.

Greenberger, E., Lessard, J., Chen, C., \& Farruggia, S. P. (2008) 'Self-Entitled College Students: Contributions of Personality, Parenting, and Motivational Factors', Journal of Youth and Adolescence 37: 1193-1204.

Levine, N. B. (2003) 'A Multidimensional Scaling Analysis of Perceptions of Academic Dishonesty Among Learning and Grade-Oriented Students', Dissertation Abstracts International 64(1175): UMI No. 3088557.

Marsh, H. W., \& Roche, L. A. (1997) 'Making Students' Evaluations of Teaching Effectiveness Effective: The Critical Issues of Validity, Bias, and Utility', American Psychologist 52(11): 1187-1197.

Page, S., \& Alexitch, L. R. (2003) 'Learning- and Grade-Orientation, Sex, and Prediction of Self-Reported Academic Performance', Psychological Reports 92: 320-324.

Race, P. (2005) Making Learning Happen. London: Sage.

Rammstedt, B., \& John, O. P. (2007) 'Measuring Personality in One Minute or Less: A 10-Item Short Version of the Big Five Inventory in English and German', Journal of Research in Personality 41: 203212.

Sabini, J. \& Monterosso, J. (2003) 'Moralization of College Grading: Performance, Effort, and Moral Worth', Basic and Applied Social Psychology 25(3): 189-203.

Säljö, R. (1981) 'Learning Approach and Outcome: Some Empirical Observations', Instructional Science 10: 47-65.

Scouller, K. (1998) 'The Influence of Assessment Method on Students' Learning Approaches: Multiple Choice Question Examination Versus Assignment Essay', Higher Education 35: 453-472.

Snyder, C. R., \& Clair, M. (1976) 'Effects of Expected and Obtained Grades on Teacher Evaluation and Attribution of Performance', Journal of Educational Psychology 68(1): 75-82. 


\section{LIST OF FIGURES}

Figure 1. Scenario level of effort and performance and perception of professors' grading fairness.

Figure 2. Scenario level of effort and performance and perception of professors' grading adequacy. 